\title{
Rheumatoid arthritis in the developing world: stepping up to the challenge
}

\author{
Bridget Hodkinson • Mohammed Tikly • Ade Adebajo
}

Received: 6 January 2014 / Revised: 12 May 2014 / Accepted: 23 May 2014 / Published online: 4 June 2014

(C) Clinical Rheumatology 2014

The 'developing' world is defined by low gross domestic product, level of education and life expectancy and includes countries in Sub-Saharan Africa, Central and South-East Asia, as well as parts of Central and South America. Financial and human resource constraints impact negatively on health outcomes of chronic diseases like rheumatoid arthritis (RA). A 46-year-old businesswoman in the Netherlands with RA is likely to have early intervention with disease-modifying antirheumatic drugs (DMARDs), resulting in disease remission or low disease activity within 6 months of symptom development [1]. In stark contrast, a 46-year-old domestic worker in peri-urban Soweto, South Africa, will probably experience late diagnosis of her RA and a delay in initiation of DMARD therapy often running into years [2]. Consequently, the South African patient is much more prone than her Dutch counterpart to develop significant functional disability and to be unemployed within 2 years of symptom onset. Moreover, the psychosocial consequences of physical disability from poorly controlled RA are likely to be more severe in this setting. Poor infrastructure leading to lack of electricity and hot water, having to carry water and use of outside toilets, inadequate public transport necessitating walking long distances, poor social support systems and social isolation may

B. Hodkinson $(\square)$

Department of Medicine, Groote Schuur Hospital and University of Cape Town, Cape Town, South Africa

e-mail: drbridget@gmail.com

B. Hodkinson · M. Tikly

Division of Rheumatology, Chris Hani Baragwanath Academic Hospital, Faculty of Health Sciences, University of the

Witwatersrand, Johannesburg, South Africa

A. Adebajo

Academic Rheumatology Group, Faculty of Medicine, University of Sheffield and Barnsley Hospital NHS Foundation Trust, Sheffield, UK be some of her key experiences [3]. Low levels of formal education impact negatively on the risk of depression, possibilities of modifying employment to accommodate disabilities, and may mean that patients take a less active role in problem-solving [4].

Moreover, in resource-constrained countries, there is limited access to biologic treatment and joint replacement surgery. There is a large burden of infectious diseases, especially HIV infection and tuberculosis (TB), which not only overwhelm health services but also present diagnostic and therapeutic challenges in patients with inflammatory arthritis. HIVassociated arthritis can masquerade as RA, and corticosteroids and anti-TNF biologics need to be used with caution because of the high risk of TB reactivation.

Given the myriad of challenges in optimising RA management, what should the priorities be? A survey in Latin American and Caribbean countries identifies a number of strategies to improve care of RA patients [5]. In our view, the most important intervention is training of health care professionals, including family practitioners, primary care nurses, occupational and physiotherapists and orthopaedic surgeons, to recognise early inflammatory arthritis and make appropriate referrals to specialist centres.

The next priority would be for rheumatology specialist centres to fast track patients with possible inflammatory arthritis and initiate DMARDs promptly. Methotrexate (MTX) is relatively inexpensive and readily available in most parts of the world and is used optimally if given early and escalated as part of a tight control strategy [6]. When used as monotherapy, MTX induces low disease activity in $20-40 \%$ of patients [7, 8], failing of which, combination DMARD therapy can be used to control disease activity. Using this strategy, only a minority of patients will have an inadequate response to traditional DMARDs and will require biologic DMARDs to control disease activity. For these patients, rheumatology groups need to lobby funders and healthcare authorities to 
provide biologics. In addition, pharmaceutical companies might improve access to biologics by reducing their cost or through schemes similar to the Glivec International Patient Assistance Program established by Novartis which provides imatinib to chronic myeloid leukaemia patients in the developing world.

Innovative qualitative and quantitative research is urgently needed to improve clinical outcomes and meet specific needs of RA patients in developing countries. Studies assessing costeffective strategies for screening and care delivery in resourceconstrained settings might also provide important lessons for the recession-hit healthcare systems of many developed countries. There are, at present, no longitudinal studies from the developing world on the effectiveness of early referral or screening tools. There is a need to develop and validate a simplified treat-to-target strategy that is mainly nurse-driven. In the context of HIV infection, a recent study has shown that a nurse-driven treatment programme is as good as one run my doctors, and moreover, patients were happier with the service [9]. Biologic registries in the developing countries will explore the safety of biologics and better define risk factors for TB.

Centres of excellence in both the developed and the developing world offer unique opportunities for exchange of skills between health professionals. It has been very encouraging to observe such mutually beneficial partnerships developing in countries such as Kenya, Zambia, India, Pakistan, Columbia, Argentina and Mexico. By designating centres of excellence in the developing world, in a similar manner to the EULAR centres of excellence, ILAR might encourage collaborations and outstanding research.

In Africa and the developing world, RA was once considered uncommon and mild, particularly in rural areas, but recent studies in Africa indicate that the prevalence of RA is increasing [10]. One explanation for this is the transition to an urban lifestyle in most developing countries. Is there the chance of limiting aspects of an affluent industrialised lifestyle that might worsen the risk of RA or its comorbidities? Sedentary lifestyle, cigarette smoking and high sugar and calorie diets with attendant increase in dental caries, obesity and other cardiovascular hazards need to be discouraged using public health approaches.

Thanks to a growing toolbox of instruments to diagnose and monitor disease, as well as excellent therapies and improved outcomes, these are exciting times for RA patients and their doctors. Rheumatologists are some of the happiest and most satisfied subspecialists in the world [11]. But do health care workers and patients around the globe share this optimistic outlook? Perhaps the concept of a 'developed' or 'developing' country, based on gross domestic product, is not the only important one. What about gross domestic happiness?
This measurement, previously the territory of barefooted sociologists, might be equally important for us as health care providers [12]. Can rheumatologists, regardless of whether we practice in an affluent or in a resource-constrained setting, step up to the challenge of providing excellent care that ensures that our RA patients are disease-free, economically active and socially fulfilled?

Disclosures $\mathrm{BH}$ has no financial disclosures to declare. MT has done consultative work done for the following pharmaceutical companies: Roche, Pfizer, Bristol Myers Squib and Abbvie. AA has received unrestricted educational funding from various pharmaceutical companies including Pfizer.

\section{References}

1. Vermeer M, Kuper HH, Hoekstra M et al (2011) Implementation of a treat-to-target strategy in very early rheumatoid arthritis: results of the Dutch Rheumatoid Arthritis Monitoring remission induction cohort study. Arthritis Rheum 63:2865-2872

2. Hodkinson B, Musenge E, Ally M et al (2012) Functional disability and health-related quality of life in South Africans with early rheumatoid arthritis. Scand J Rheumatol 41:366-374

3. Schneider M, Manabile E, Tikly M (2008) Social aspects of living with rheumatoid arthritis: a qualitative descriptive study in Soweto, South Africa - a low resource context. Health Qual Life Outcomes 6: 54

4. Margaretten M, Barton J, Julian L et al (2011) Socioeconomic determinants of disability and depression in patients with rheumatoid arthritis. Arthritis Care Res (Hoboken) 63:240-246

5. Massardo L, Suarez-Almazor ME, Cardiel MH et al (2009) Management of patients with rheumatoid arthritis in Latin America: a consensus position paper from Pan-American League of Associations of Rheumatology and Grupo Latino Americano De Estudio De Artritis Reumatoide. J Clin Rheumatol 15:203-210

6. Hodkinson B, Monyai N, Tikly M (2013) The Utility of Clinical Disease Activity Index for tight control of disease activity in South African Rheumatoid Arthritis patients. Ann Rheum Dis 27:205

7. Emery P, Breedveld FC, Hall S et al (2008) Comparison of methotrexate monotherapy with a combination of methotrexate and etanercept in active, early, moderate to severe rheumatoid arthritis (COMET): a randomised, double-blind, parallel treatment trial. Lancet 372:375-382

8. Moreland LW, O'Dell JR, Paulus HE et al (2012) A randomized comparative effectiveness study of oral triple therapy versus etanercept plus methotrexate in early, aggressive rheumatoid arthritis. Arthritis Rheum 64:2824-2835

9. Sanne I, Orrell C, Fox MP et al (2010) Nurse versus doctor management of HIV-infected patients receiving antiretroviral therapy (CIPRA-SA): a randomised non-inferiority trial. Lancet 376:33-40

10. Adebajo AO (1991) Rheumatoid arthritis: a twentieth century disease in Africa? Arthritis Rheum 34:248-249

11. O'Dell J. The happiest specialty: rheumatology is \#1! The Rheumatologist 2012; http://www.the-rheumatologist.org/details/ article/2196571/The_Happiest_Specialty_Rheumatology_Is_1.html

12. Pennock M, Karma $\bar{U}$. Gross national happiness as a framework for health impact assessment. http://dx.doi.org/10.1016/j.eiar.2013.07.27 